\title{
Community informatics social network for facilitated community policing: A case study of Nigeria
}

\author{
Chinedu Pascal Ezenkwu ", Simeon Ozuomba, Constance kalu \\ Department of Electrical/Electronics and Computer Engineering, University of Uyo, Uyo, Akwa Ibom State, Nigeria
}

Email address:

edusco4@gmail.com(C. Ezenkwu),simeonoz@yahoo.com(S. Ozuomba),constkay4@yahoo.com(C. Kalu)

To cite this article:

Chinedu Pascal Ezenkwu, Simeon Ozuomba, Constance kalu. Community Informatics Social Network for Facilitated Community Policing: A Case Study of Nigeria. Software Engineering. Vol. 1, No. 3, 2013, pp. 22-30. doi: 10.11648/j.se.20130103.12

\begin{abstract}
Community Policing is a policing strategy that aims at creating an atmosphere that promotes police-public partnership in providing proactive and active solutions to crimes in a community. Although, the police-initiated and policedriven community policing pilot project that has been operative in Nigeria for almost a decade now has recorded several success stories, yet the rates of crimes and insecurities in the country keep escalating tremendously. In this paper, Community Informatics Social Network for Facilitated Community Policing (CISN4FCP) is proposed to address the issue. In the proposed CISN4FCP scheme, online GeoHubNet Community Structure (OGCS) is used to organise online geocommunities for local communities in various states in Nigeria. Furthermore, for each online geo-community, an online community hub for facilitated community policing is established. The CISN4FCP is a software intensive system; hence, its development follows a Community Centric Incremental Software Development Methodology (CCISDM). In order to ensure the system usability, sociability and flexibility to changes that may crop up at the later stage of its evolution, an agile Evolutionary Community-Centric Requirement Engineering Process (ECCREP) is adopted for the system development, evaluation and support.
\end{abstract}

Keywords: Community Informatics, GeoHubNet, Community Policing, Community Hub Facilitator, Community Network, Geo-community, Crime, Crime Mapping

\section{Introduction}

Without doubt, it is in the best interest of every community to enjoy serenity in its environment. However, nowadays, Nigerians are witnessing growing rate of crimes, terrorism and decadence. In such situation, the competence of the Nigeria police and other law enforcement agencies are being questioned. Furthermore, the involvement of the citizens in supporting the policing process is absolutely imperative. It was as a result of this that a pilot community policing project was launched in Nigeria on April 27, 2004, by former President Olusegun Obasanjo.

Basically, community policing is a policing strategy adopted for the purpose of creating an atmosphere that will encourage partnership between the police and a community in combating crimes in the community. Remarkably, the police-initiated and police-driven community policing pilot project in Nigeria has so far not been effective in addressing the growing insecurity problems in the country. Among various reasons for this poor performance are fear on the part of the citizens of being noted as police informants by hoodlums; certain negative beliefs about the police; risks of favouritism, nepotism and development of corrupt networks due to police closeness with the people, etc. In addition, the scheme does not have any significant technology support to facilitate its operations and citizens' engagement.

In view of the problems inherent in the existing policeinitiated and police-driven community policing scheme in Nigeria, in this paper, a Community Informatics Social Network for Facilitated Community Policing (CISN4FCP) is proposed. The CISN4FCP is built on the triple factors, namely, Community Informatics, Social Network and Independent facilitator driven framework. Community Informatics (CI) is the application of Information and Communication Technology (ICT) to enable and empower Community process such as community development and in this case, community policing [1]. Social network sites are web-based services that allow individuals to construct profiles, display user connections, and search and traverse within that list of connections [2].In recent years, online 
social network has become a veritable tool for CI experts.

Unlike the traditional police-driven community policing scheme, the CISN4FCP is designed in such a way that an independent facilitator will initiate and drive the community policing scheme by using the social networking tools, Geographic Information System (GIS), database technology, multimedia tools and Online GeoHubNet Community Structure (OGCS) for building active community networks [3]. The system uses both synchronous and asynchronous communication mechanisms to encourage candid opinions from the community members. Such mechanisms include toll-free hotlines, anonymous phone call facility, anonymous email, discussion forum, Google map mash-up application, incident report forms, "Help-me" forms, crime appeal form and anonymous membership account on the online community. These communication mechanisms employed are provided with considerations to users' privacy, data security and information integrity. Equally, the independent facilitator will take the responsibility for reporting those cases that individuals or community groups may find difficult to communicate directly to the police. In this case, the community members or groups can use the various anonymous communication channels provided on CISN4FCP to relay their complaints to the independent facilitator who then follows the laid down complain management procedure to relay the information to police if need be.

Furthermore, some cases may require rehabilitation or counselling of community members. Such cases include drug addiction, juvenile delinquency, prostitution and other similar cases. Such situations will require the services of rehabilitation centres and experts. As such, the independent facilitator is required to collaborate with wide range of organisations including the community members, the police, other security agencies, NGOs, organisations that provide social services cum welfare services to community members. Consequently, as part of their services, the independent facilitator enables community members to connect with various social and welfare service providers.

Finally, the CISN4FCP has some built-in mechanism for continuous evaluation of the expectations and participation of the system stakeholders, as well as system's outcomes and social impact assessments in the various local communities it supports.

\section{Review of Relevant Literatures}

\subsection{Community Policing}

"Reference[4] opined community policing is a strategy of crime management that deals with the basic causes of crime with the view to developing and applying longer term solutions to resolving issues through improved police community partnership and communication." In addition, [5] states that "the police are the public and the public are the police; the police being only members of the public who are paid to give full time attention to duties which are incumbent on every citizen in the interest of community welfare and existence." The traditional policing has three operational pillars: the pillar of random or unstructured routine community patrols, usually within a designated geographical location; the pillar of rapid response to calls from community residents; and the pillar of retroactive past crime investigations [6]. However, community policing is a proactive "approach toward crime that addresses the underlying causes of crime and endeavors to apply long term problem-solving to issues through improved policecommunity partnerships and communications" [4] The traditional policing is incident-driven [7], while community policing is cause-driven. [5] suggests that "the police are the public and the public are the police; the police being only members of the public who are paid to give full time attention to duties which are incumbent on every citizen in the interest of community welfare and existence". [8] opined that "community policing comprises of three key components: community partnership, organisational transformation and problem-solving." This synergistic approach to policing is tailored to the following goals:

(a) creation of a conducive environment where everyone can particpate in curbing crimes

(b) maintenance of trust between the citizens and the law enforcement agencies

(c) development of a framework that will make it convenient for the citizens to relate information pertaining to possible terrorists' threats and infrastructure vulnerabilities

(d) efficient anaysis of information from the citizens and the development of the optimal response strategy. [9] asserts that "thought and analysis is fundamental to problem-oriented policing in order to effectively respond to the cause of the problem"

(e) Integration of the community policing philosophy into the mission statement of the law enforcement agencies.

\subsection{Community Policing in Nigeria}

In Nigeria, a pilot community policing project was launched on April 27, 2004, by former President Olusegun Obasanjo. The idea was to improve the police-public relation which is imperative for proactive policing. Although this strategy has recorded some success stories, however the growing tension, terrorism and civil unrest in various communities across the nation show that there is need for improvement in the community policing strategies in the country. Notably, the factors that contributed to the poor performance of the existing Community policing strategy among others are:

- Selective delivery of police and security services [10].

- The citizens' fear of being noted by hoodlums as police informants

- Certain negative beliefs about the police by the citizens 
- Lack of convenient and friendly platform for divulging crime information

- No safe platform for providing guidance and support for citizens who wish to renounce crimes and tread the path of decorum.

- Development of preferential treatments and corrupt networks due to the police closeness to the communities.

\subsection{Existing Community Policing Technologies}

Some technology advances for community policing are explained in this section.

i). Telephonic Advances: This involves the use of telephone along with other inventions such as automobile and two-way radio for policing. The most common use of telephone is the use of police emergency lines such as 911 (used in Baltimore, MaryLand)[11]. The use of this approach has placed a lot of burden on the law enforcement agencies due to incessant calls on trivial quarrels between neighbours or minor crimes. In Baltimore, a three-digit alternative-311 was developed for use as a non-emergency numbers. In Addition to the emergency and non-emergency numbers, other telephonic technologies have also been adopted for community policing.

a) Computer Aided Dispatch (CAD) System: Traditionally, crime calls from citizens are manually prioritized on the basis of whether an immediate police response is necessary, or whether a delayed or alternative response will suffice. CAD system is dedicated to the function of prioritizing calls from citizens for police services. CAD was developed by Telecom (now Telstra) in 1990, for the Queensland Police Service to aid radio communication and to dispatch jobs to operational police in Brisbane, Australia [12].

b) Auto-dialling Alert Network: The computerized Auto-dialling Alert Network is also known as "reverse-911". This is based on the fact that it was used in the opposite sense as the 911. The AutoDialling Alert Network allows the law enforcement agencies to send pre-recorded messages containing information about crime trends, suspicious persons and suggestions to minimize victimization to all telephones in a pre-defined area or neighbourhood.

ii). Computerized Advances: The knowledge of the police about their beats and the people they police is of immense importance for efficient policing. This knowledge is categorised into local knowledge and local acquaintance [13]. Local knowledge refers to the knowledge a police officer has about his/her beat while Local acquaintance is a type of knowledge that a police officer has about the people he/she polices. Through this knowledge an officer is capable of understanding his/her beat, the people that make up the community, their problems and priorities. This will enable him/her to devise the best strategies for tackling the community's problems in the supposed order. In the past, this knowledge remains restricted and useful only to the individual that possesses it. However, the advent of the computer has initiated a means of collating, storing and sharing such knowledge without stress. Some of these computerized advances include Mobile Digital Terminal (MDT), Crime Mapping, In-House Data Analysis Program and Websites.

a) Mobile Digital Terminal (MDT): MDTs are used in conjunction with the CAD systems. By the aid of incar computers, officers can have firsthand information about a crime before their arrival to the scene and also, MDTs provide officers with direct access to other relevant information such as motor vehicle registrations, drivers' licenses, and outstanding warrants directly, without having to wait for a dispatcher to run a computer check. Officers can as well enter police reports into the computer while out in the field, rather than having to return to the police station early to complete paperwork. Finally, MDTs can also allow officers send e-mail to other officers, including those who are not on duty at the time[11].

b) Crime Mapping: A crime mapping software is software that employs Geographic Information System (GIS) technology for the purpose of detecting and tracking patterns of crimes in a given area. Some applications like Google Mashup which allows users to add features on Google Map, are used for this purpose.

- In-House Data Analysis Program: This software is used to gauge the success of the police efforts to remedy a problem. With this software, the officer is advised on the best approach to adopt in tackling the problems [11].

- Websites: Police websites are of immense importance for effective policing. they facilitate the interaction between police and the public. Websites can allow citizens provide crime information, information about missing persons or properties etc via police email or other contacts available on their websites.

\subsection{Community Informatics Social Networks (CISN)}

The idea of digital divides is gradually petering out of various communities due to the ubiquity of smart-phones, tablets, notebooks, internet and social network applications. This has greatly improved the problem-solving approaches of these communities by encouraging the adoption of Information and Communication Technology (ICT) in proffering solutions to their respective challenges. This ICT driven problem-solving technique is termed community informatics, alternatively known as grassroots computing. Community informatics is an emerging field focusing primarily on the interaction between local communities and ICT and a more particular focus within social informatics [1]. The ubiquity of social networks such as facebook, twitter, linkedln, Google+, myspace, Flickr etc has to a great extent encouraged collaboration and information sharing among people. "Reference [13] opined that social 
media is a new kind of online media characterized by user participation, openness, conversation, community, and connectedness."

\section{Research Methodology}

\subsection{System Description and Design Procedure}

The CISN4FCP is a software intensive system. As such, a Community-Centric Incremental Software Development Methodology (CCISDM) is used in the development of the system. This methodology is adopted to improve the system usability, sociability and flexibility to changes that may crop up at the later stage of the development. The activities involved in the system development include requirement engineering, planning, design, coding, testing and release, as depicted in Fig. 3.1.

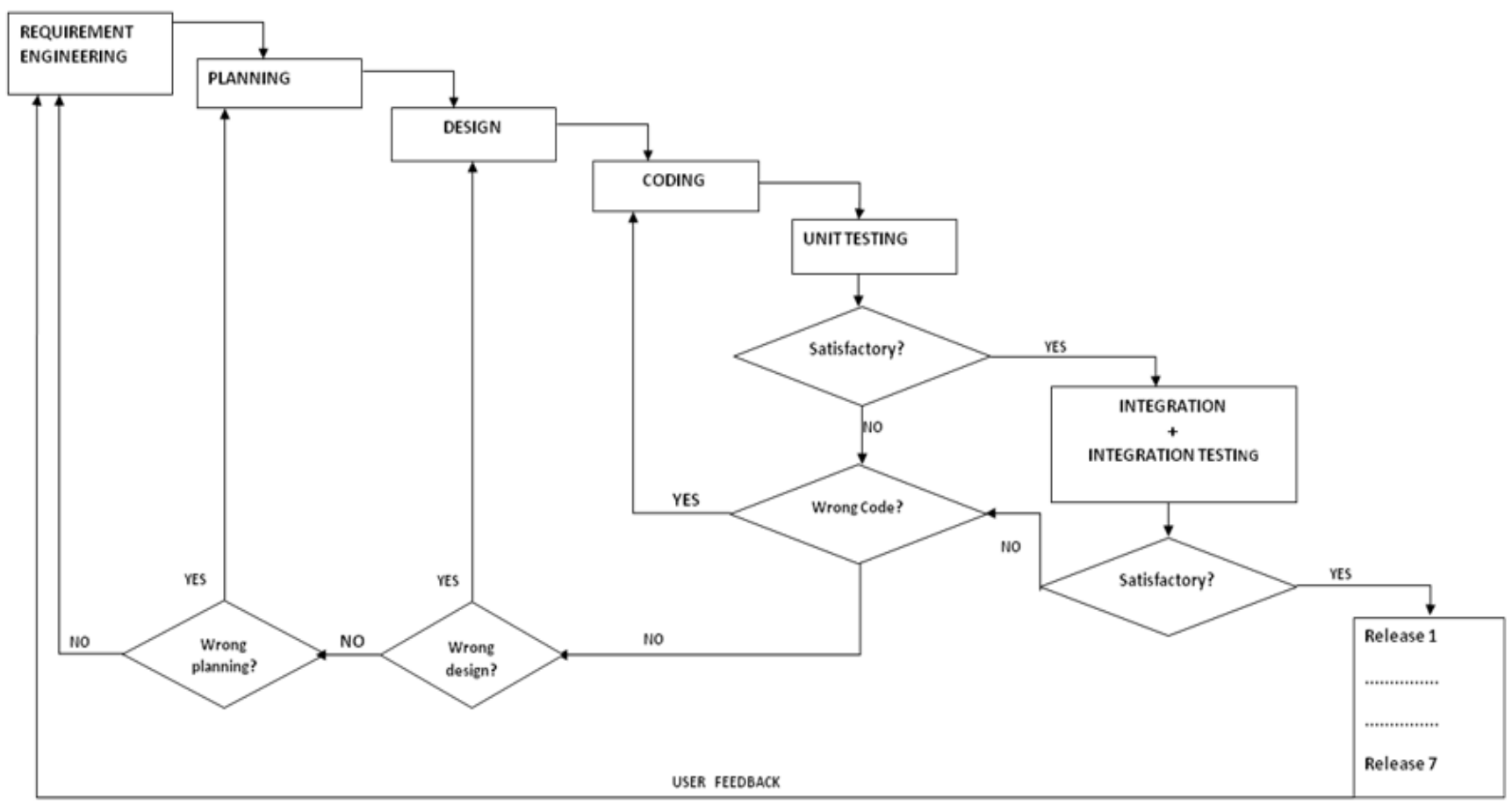

Fig 3.1. Community-Centric Incremental Software Development Methodology (CCISDM)

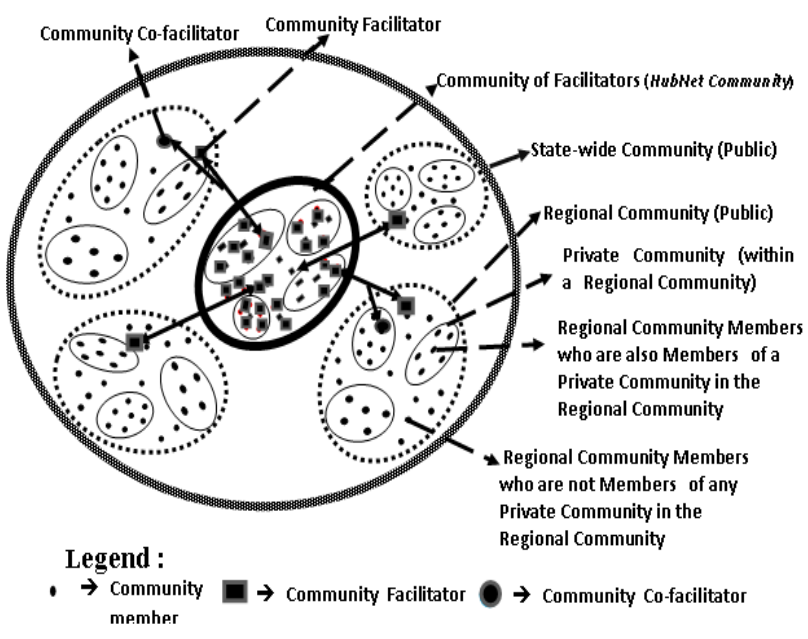

Fig 3.2. Scalable Online GeoHubNet Community Structure (OGCS). Source: [3]

The work entails development of a social network web application that will support the best practices and strategies for community policing. Most importantly, the system adopts a facilitated approach to community policing, which means that a facilitator agent or organisation initiates, controls, manages, and sustains the participation of diverse stakeholders of the proposed system. On the other hand, the usefulness of any online social network relies on the formation of online community, which consists of people that connect and interact on that particular social network platform base on the purpose defined by the social network. Consequently, the system uses an online geo-community governance structure to guide in the creation and management of online geo-communities on the social network. Specifically, the GeoHubNet community structure is a hub-firm organisation structure for a hub-firm facilitated social process such as community development and other collective actions. The detailed design of the GeoHubNet is presented in Fig 3.2.

In order to attract and sustain the active participation of diverse community policing stakeholders in the system, the system adopts a community hub for community policing as a strategic tool. The conceptual framework of the system showing the community policing hub is depicted in Fig.3.3. Section 3.4 presents the detailed modular and functional decomposition of the system.

Meanwhile, before any design could take place, requirement engineering process is conducted. Requirement 
engineering is presented in section 3.5, along with the requirement engineering model of Fig.3.5.

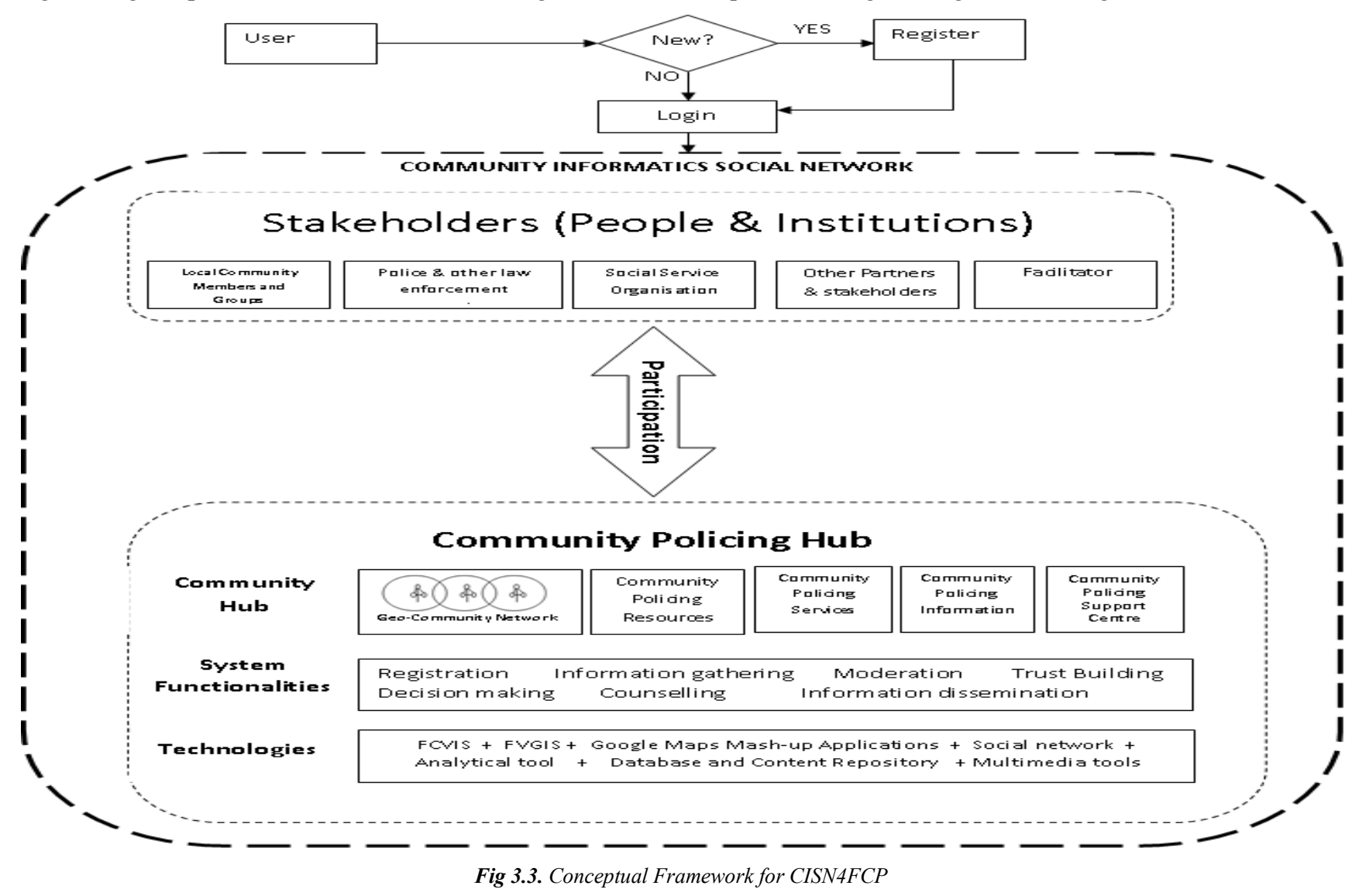

Legend: FCVIS $=$ Facilitated Community Volunteer Information System FVGIS $=$ Facilitated Volunteer Geographic Information System

\subsection{The Online Community Structure for the CISN4FCP}

The scalable online GeoHubNet community structure (Fig.3.2) is used to organise and manage online communities in the CISN4FCP. GeoHubNet organizes online communities according to certain geopolitical divisions such as nationwide, state-wide, regional or citywide geo-communities. Fig. 3.2 shows a state-wide GeoHubNet structure. Inside the state-wide GeoHubNet structure are regional geo-communities representing citywide, senatorial or local government geo-communities within that state. Within each regional local community in the state are local groups, institutions and individuals who are members of the online geo-community. Each regional geo-community has a set of facilitators and possibly along with co-facilitators that moderate the interconnection and interaction of the members in that regional community. The facilitator also conducts regional community network weaving. The collection of all the regional community facilitators in a state make up the hub firm network called the HubNet. The HubNet in this case are actually the local community organization that champions the community policing improvement program. In other words, the HubNet is the facilitator organization for the CISN4FCP project.

\subsection{The CISN4FCP Online Community Policing Hub}

In order to ensure active participation of local community members and other stakeholders in the community policing scheme, the CISN4FCP employs online community policing hub for each local community. Specifically, the CISN4FCP operates as follows:

i Uses the Scalable Online GeoHubNet Community Structure (OGCS) to establish and coordinate online geo-community for each local community in the various states across the nation.

ii creates facilitated online community policing hub for each of the online geo-community as shown in fig. 3.3. Basically, each online community policing hub is a one spot or virtual space on the internet where the resources, services, opportunities, local groups, local information and discussions, etc that are relevant for community policing in any given local community are made visible and accessible. The online community policing hub is built through strategic community network weaving, Facilitated Community Volunteer Information System (FCVIS) and Volunteer Management System (VMS). In Addition, the system employs Google Maps mashup applications to support Facilitated Volunteer Geographic Information (FVGI). 
iii Through the use of various online and offline community network weaving strategies, the facilitator builds strong and active community networks for each local community. The community networks are strategically interconnected with relevant groups, institutions and partners so as to realise effective and sustainable community policing in each local community.

iv The Facilitated Community Volunteer Information System (FCVIS) and the Facilitated Volunteer Geographic Information (FVGI) with Google Maps mash-up applications enable facilitated usergenerated information; community crime mapping; social validation of contents, community members and issues being discussed; request for community support, anonymous and safe crime reporting, etc.

v The Volunteer Management System (VMS) enable community members and other community policing stakeholders to volunteer resources, services etc in support of the community policing scheme. The VMS enable the facilitator to coordinate the volunteered items, the volunteers and the beneficiaries as well.

vi In addition, the CISN4FCP also has other generic social network functionalities which allows registration of members on the social network, discussion forum, management of personal profiles and networks, etc.

In Fig 3.3, the circles represent the community members in a given geo-community. The community members can access and use the system functionalities. Their activities are moderated by a facilitator. The technologies employed y the system are equally shown in the diagram. The combination of these technologies and various other strategies are used to address the community policing objectives and goals in each local community.

\subsection{Functional Decomposition of the System}

The system modules are shown in Fig 3.4a. Each module is further decomposed into its respective sub-modules as shown in Fig. 3.4b, 3.4c, 3.4d, 3.4e, 3.4f, 3.4g and 3.4h. The detailed explanations of the system modules and submodules are presented in section 3.6

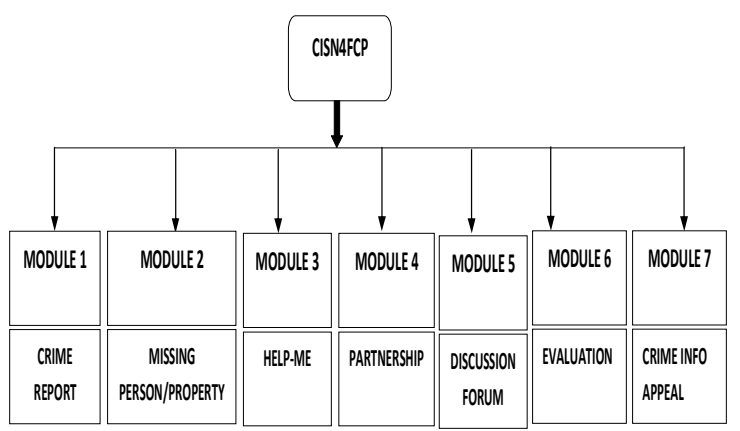

Fig 3.4a. Modular Decomposition Of The System

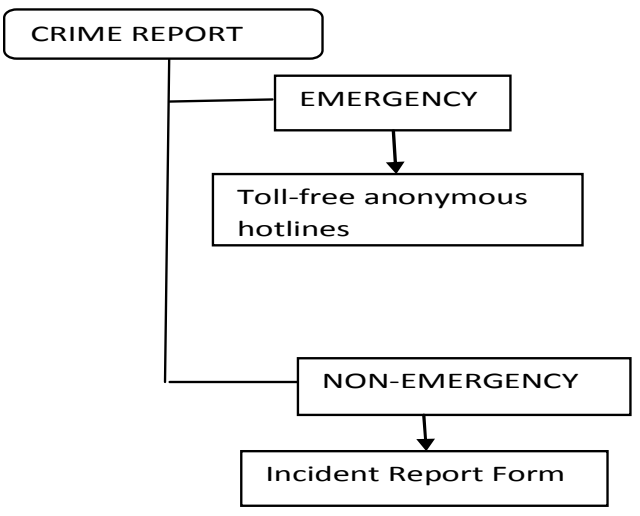

Fig 3.4b. Functional Decomposition of the Crime Report Module

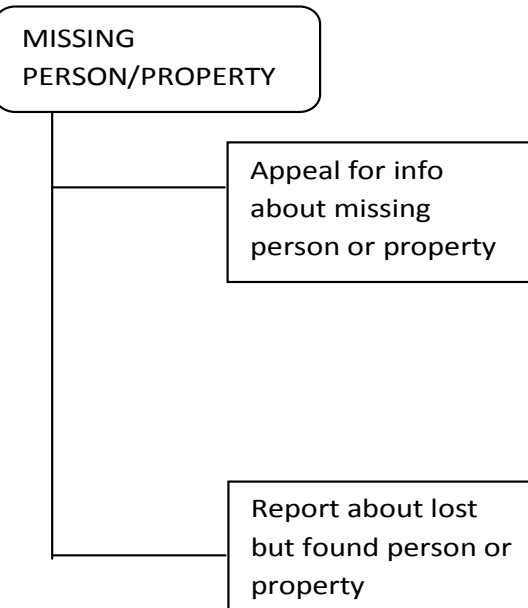

Fig 3.4c. Functional decomposition of the missing person/property module

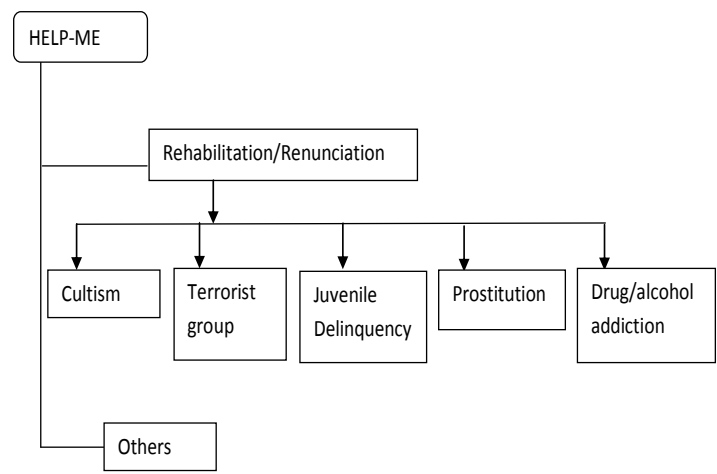

Fig 3.4d. Functional decomposition of the help-me module

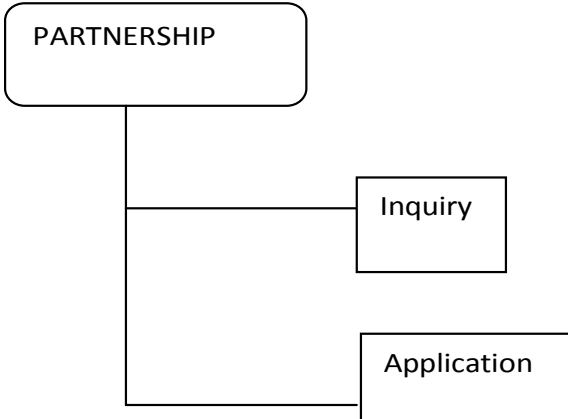

Fig 3.4e. Functional decomposition of the partnership module 


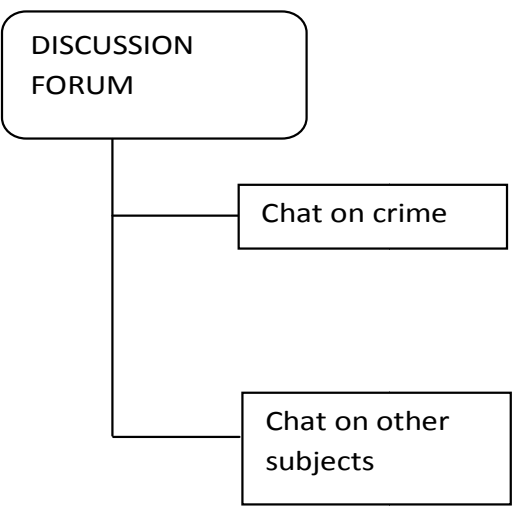

Fig 3.4f. Functional decomposition of the discussion module

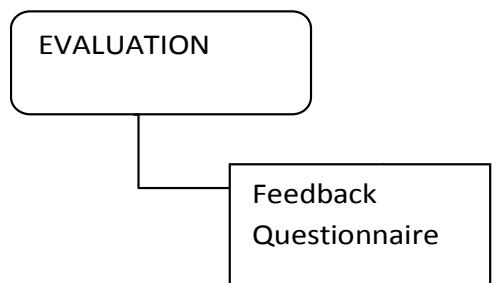

Fig 3.4g. Functional decomposition of the evaluation module

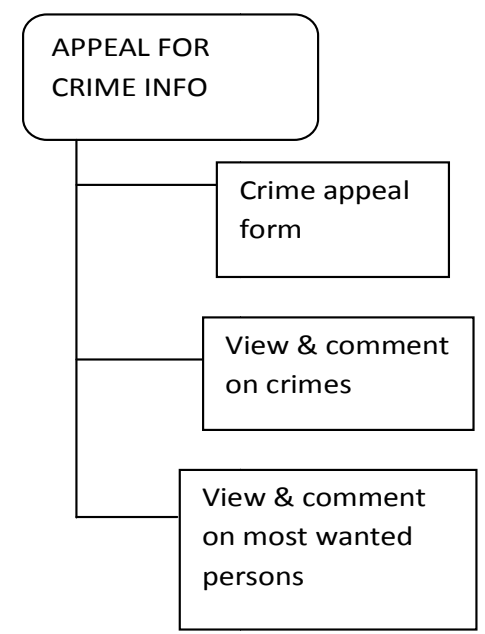

Fig 3.4h. Functional Decomposition Of The Crime Info Appeal Module

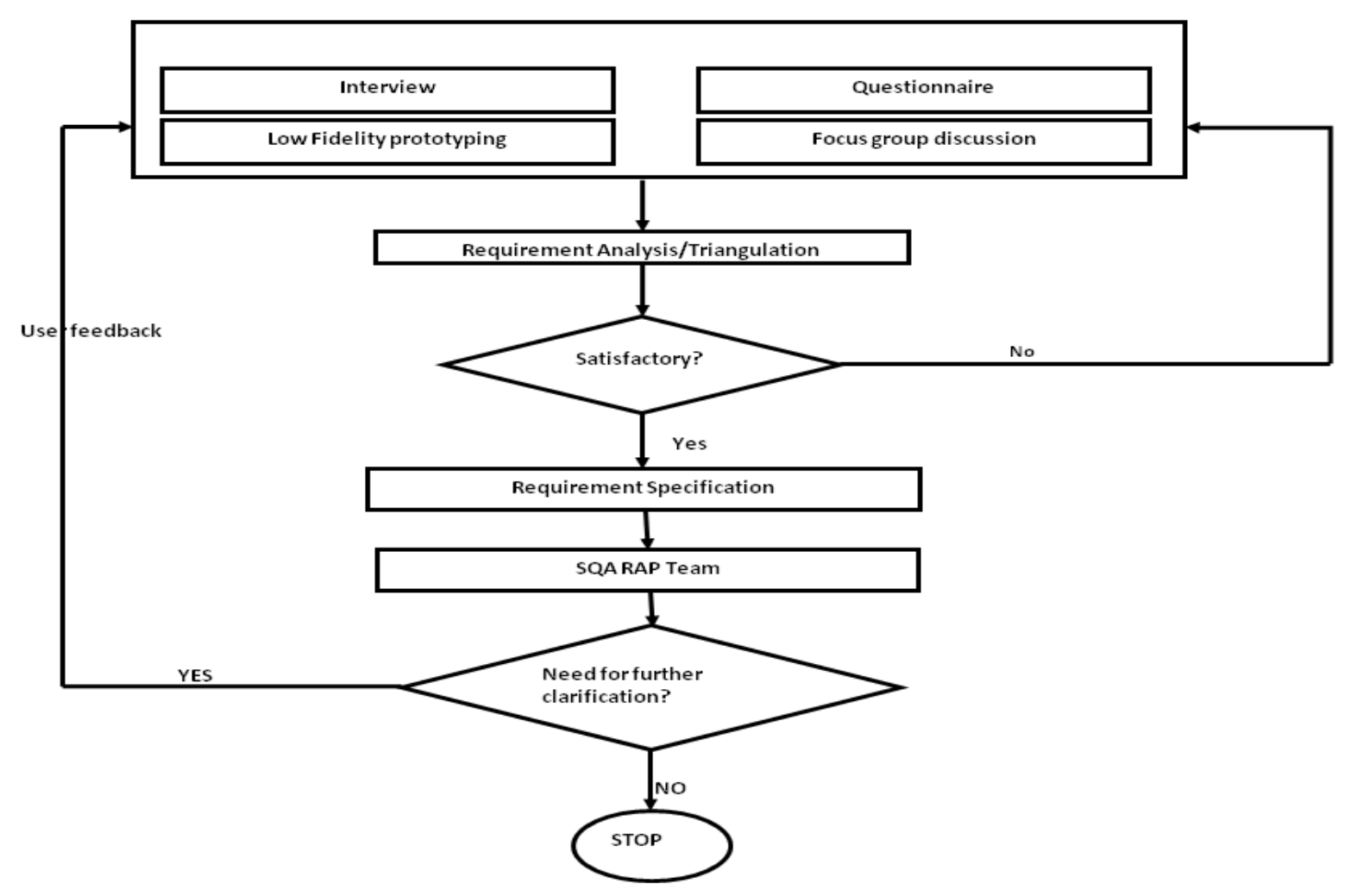

Fig 3.5. ECCREP model

\subsection{Requirement Engineering for the System}

An Evolutionary Community-Centric Requirement Engineering Process (ECCREP) is adopted for the system. The rationale for the adoption of ECCREP approach is the belief that although the community members may not have the technical proficiency needed to develop the system, yet, they are better professionals in their problems and their needs may vary in the course of the system development. The activities in this stage include the requirements elicitation; requirements analysis; and documentation which give rise to the requirements specification. The ECCREP model is depicted in Fig. 3.4. Interview, questionnaire, focus group discussion, and low fidelity 
prototyping were used to elicit the users' and system's requirements. The requirements are analyzed and triangulated to ensure that the requirement specification is free of inconsistency, ambiguity, redundancy, etc. Focus group feedbacks and comments are sought for at each stage of the requirement engineering process to facilitate a complete requirement specification that is tailored to the community's needs. The Requirement Specification further undergoes technical reviews by the Rapid Assessment Process (RAP) team constituting the project supervisor, research assistants and domain experts in diverse fields that are relevant to the research for Software Quality Assurance (SQA). During this process, the focus group, literature review and other stakeholders may be consulted for further clarifications if need be.

\subsection{Functional Requirements of the System}

Crime report module: This module allows users to report crime to the facilitator.

- $\quad$ The Emergency crime reports category provides faster, secured and free way of reporting crimes that require immediate attentions. Toll-free anonymous hotlines are provided for easy communication of crimes info to the facilitator.

- The non-emergency crime reports category provides crime reporting techniques for crimes that do not require immediate attention. These crimes are reported by the aid of an incident report form. This form supports multimedia message, and allows the reporter to send the coordinate of the incident area for crime mapping.

Missing persons/properties module: This system module permits users to appeal for information about the whereabouts of lost persons or properties as well as to report lost but found persons or properties. The pictures as well as other necessary descriptions of the persons or things that are lost or found are provided as guides.

iii. Help-me module: The 'HELP-ME' module presents rehabilitation, counseling, support and protection opportunities to community members who wish to renounce their evil gangs, addictions, anti-social behaviours, etc. A well-structured 'HELP-ME' form is provided for collection of vital information from such persons, who are availed with the services of rehabilitation centres and other partnering experts depending on the area of help.

Partnership module: This module provides partnership opportunities to law enforcement agencies, churches, social service organisations, companies, NGOs, businesses, institutions and other stakeholders. The module has two functionalities:

- Inquiry: This allows the intending partners or sponsors to ask questions about terms, conditions and also visualize necessary programmes, schemes, activities and events where their sponsorships and supports may be needed.

- Application: This provides application forms for the partners to sign up their memberships or partnerships

Discussion forum: This is a collaborative platform where the community members and other users can meet, collaborate and exchange ideas using Instant Messaging(IM) and other social networking services. The discussion forum is categorized into Crime Chat Forum and Public Chat forum.

- $\quad$ The Crime chat forum allows a user to appear as unknown or with an alias in order to keep him/her unknown from other users. This platform is the best for discussions pertaining to crimes in the community.

- The public chat forum is mainly to build active community networks and trust among the community members. The community members meet, know one another and discuss other personal issues that may not be crime related.

Evaluation module: The impact assessment of this system on the community is achieved through this module. The module provides a 'feedback questionnaire' which enables the community members to state their expectations as well as the areas of deficiencies of the system. The information collected are collated and the results are used as a veritable tool for decision support.

vii. Crime info appeal module: This module enables the police and other law enforcement agencies to appeal for certain crime information and information about most wanted persons. It also helps the facilitator to verify more about certain crime reports.

- $\quad$ The crime appeal form is provided for this purpose. This module supports multimedia message which enables the pictures of the most wanted persons to be displayed for identifications.

- Users can view the appeal, make their comments or use the communication channels provided in the crime report to relate the info which they feel should be private.

\section{Conclusion}

In this work, a Community Informatics Social Network for Facilitated Community Policing (CISN4FCP) in Nigeria has been presented. First, the challenges faced by the existing police-initiated and police-driven community policing pilot project in Nigeria are highlighted. Then, the methodology and tools used in the development of CISN4FCP are presented, namely, the Community-Centric Incremental Software Development Methodology (CCISDM), the Evolutionary Community-Centric Requirement Engineering Process (ECCREP) and the Scalable Online GeoHubNet Community Structure (OGCS). Furthermore, the functional decompositions of the system as well as detailed explanations of each functional unit are also discussed and illustrated with relevant diagrams. 


\section{References}

[1] M. Gurstein," What is Community Informatics?,"Monza: Polimetrica, 2007.

[2] D. Boyd, and N. Ellison,Social, "Network sites, definition, history and scholarship," 2007. http://jcmc.indiana.edu/vol13/issue1/boyd.ellison.html

[3] S. Ozuomba, G. A. Chukwudebe, F. K. oKPARA and M. Ndinechi, "Social Networking Technology: A frontier of communication fordevelopment,"2013. Available at: http://epromac.com.ng/onddc/paper/GeoHubNet.pdf

[4] J. S. Dempsey and L. S. Forst, "An introduction to policing", $4^{\text {th }}$ ed., Madison and Wadswort: Belmont. 2008.

[5] C. H. Weigand, "Combining tactical and community policing considerations. Law and Order," May, 1997, pp 7071.

[6] O. U. Godwin, R. O. Arop and A.F. Ahmed," POS102 Police community relations and interpersonal relations and awareness," Lagos: National Open University Of Nigeria. 2009

[7] H. Goldstein, "Towards community-oriented policing: potential, basic requirements and threshold questions. Crime delinquency (Volume 33)," 1997, pp 6-36.

[8] M. Chene, " Community policing as a tool against corruption," Transparency International, 2012. pp 2.

[9] M. H. Moore, "Problem solving and community policing: A preliminary assessment of new strategies of policing," "Modern policing crime and justice volume 15", eds. Michael Tonry and Norval Morris (Chicago: University of Chicago Press, 1992), 1992, 99-158.
[10] M. Müller, "Community policing in Latin America": lessons from Mexico City, 2010. http://www.ssrnetwork.net/document_library/detail/5722/co mmunity-policing-in-latin-america-lessons-from-mexicocity

[11] S.C. Meghan, "Technology to enhance community and problem-oriented policing," Michigan: School of Criminal Law, Michigan State University. 1999.

[12] J. Chan, D. Brereton, M. Legoz, S. Doran, "E-policing: The impact of Information Technology on police practices," Queensland: Criminal Justice Commission. 2001.

[13] M.K. Sparrow, "Information systems: A help or hindrance in the evolution of policing?," Police Chief, Vol. 58, 1991, No.4.

[14] Mayfield, "What is social media? iCrossing," Updated 01 Aug, 2008.

Retrievedfrom:http://www.icrossing.co.uk/fileadmin/upload s/eBooks/What_is_Social Media_iCrossing_ebook.pdf.

[15] D.H. Bracey, "Police corruption and community relations: community policing," 1992,Retirevedfrom:http://ibs.colorado.edu/cspv/infohouse/ violit/violitDetails.php?re cordnumber $=9195 \&$ vio_name $=$ violit

[16] Law Enforcement News, "Community policing gets a hightech boost with auto-dialing alert network," October 15, 1997.

[17] R.S. Pressman, "Software Engineering: A practitioner's approach". $7^{\text {th }}$ ed., Mc Graw Hill. 2010

[18] A. Leszek, M. Bruc, L. Liong with contributions from S. Bills, "Practical Software Engineering: A Case Study Approach". Pearson Education Limited. 2005. 